\title{
Obstructive Sleep Apnea and Testosterone Deficiency
}

\author{
Sung-Dong KimiD, Kyu-Sup Cho ${ }^{(\mathbb{D}}$ \\ Department of Otorhinolaryngology and Biomedical Research Institute, Pusan National University Hospital, Pusan National University \\ School of Medicine, Busan, Korea
}

Obstructive sleep apnea (OSA) is a common disorder characterized by intermittent hypoxia and sleep fragmentation. OSA in middle-aged men is often associated with decreased testosterone secretion, together with obesity and aging. Although OSA treatment does not reliably increase testosterone levels in most studies, OSA treatment with testosterone replacement therapy (TRT) may not only improve hypogonadism, but can also alleviate erectile/sexual dysfunction. However, because TRT may exacerbate OSA in some patients, patients should be asked about OSA symptoms before and after starting TRT. Furthermore, TRT should probably be avoided in patients with severe untreated OSA.

Keywords: Continuous positive airway pressure; Erectile dysfunction; Sexual dysfunction, physiological; Sleep apnea, obstructive; Testosterone

This is an Open Access article distributed under the terms of the Creative Commons Attribution Non-Commercial License (http://creativecommons.org/licenses/by-nc/4.0) which permits unrestricted non-commercial use, distribution, and reproduction in any medium, provided the original work is properly cited.

\section{INTRODUCTION}

Obstructive sleep apnea (OSA) is a relatively common chronic sleep disorder characterized by repeated episodes of complete or partial upper airway obstruction during sleep, resulting in oxygen desaturation, sleep fragmentation, and daytime sleepiness [1]. Population-based studies suggest that $2 \%$ of women and $4 \%$ of men over the age of 50 years have symptomatic OSA [2]. A number of negative health effects have been attributed to untreated OSA including increased rates of mortality, cardiovascular disease, and neurocognitive difficulties. Untreated OSA has been demonstrated to be an independent risk factor for cardiovascular morbidity including hypertension, coronary heart dis- ease, congestive heart failure, arrhythmias, pulmonary hypertension, stroke, sudden death, insulin resistance, and gastroesophageal reflux disease [2-4].

OSA has also been associated with altered pituitarygonadal function and sexual dysfunction, manifested primarily as erectile dysfunction (ED) and decreased libido [5]. Testosterone, the primary androgenic hormone in males, is stimulated through pulsatile secretion of luteinizing hormone ( $\mathrm{LH})$ and follicle-stimulating hormone (FSH) [6]. The amount of testosterone synthesized is regulated by the hypothalamic-pituitarytesticular axis [6,7]. Serum testosterone has been shown to be lower in men with OSA and treatment of OSA may help improve hypogonadism and sexual function [7-9]. This article reviews recent investigations on the

Received: Feb 26, 2018 Revised: Mar 12, 2018 Accepted: Mar 13, 2018 Published online May 16, 2018

Correspondence to: Kyu-Sup Cho iD https://orcid.org/0000-0002-4381-6996

Department of Otorhinolaryngology and Biomedical Research Institute, Pusan National University Hospital, Pusan National University School of Medicine, 179 Gudeok-ro, Seo-gu, Busan 49241, Korea.

Tel: +82-51-240-7824, Fax: +82-51-246-8668, E-mail: choks@pusan.ac.kr 
relationship between OSA and testosterone deficiency.

\section{NORMAL SLEEP AND TESTOSTERONE}

Normal sleep is basically divided into non-rapid eye movement (NREM) and rapid eye movement (REM) sleep [10]. NREM sleep accounts for $75 \%$ to $80 \%$ of total sleep time, and REM sleep accounts for the remaining $20 \%$ to $25 \%$ [11]. These two categories of sleep have a 90 minutes cycle, and normal adults repeat this cycle four to six times during the night. The cycle becomes longer and more frequent over the course of sleep. NREM sleep can be divided into three stages depending on the depth of sleep; the first two stages (stage 1 and 2) are characterized by brief waking episodes, and are shallow. The last and deeper stage of NREM sleep (stage 3) occurs predominantly during the early stage of the sleep cycle and becomes shorter thereafter [10,11]. REM sleep appears behind NREM sleep and is predominant in the late stage of the sleep cycle. The first REM sleep appears 80 to 100 minutes after the start of sleep, and the time between the first REM sleep and sleep onset is termed the REM latency [10,11]. Sleep architecture changes naturally with aging so that the relative amount of stage 1 and 2 of NREM sleep increases and that of stage 3 decreases, especially in men [12]. Furthermore, the frequency of awakening and REM latency also increase during sleep with aging $[12,13]$.

The endogenous rhythm of testosterone production is similar to that of cortisol [14]. Serum testosterone levels vary in a circadian manner, being higher during waking hours and the decreasing to a low level at the end of the day [15]. Testosterone levels begin to rise upon falling asleep, peak at about the time of the first episode of REM sleep, and remain at the same level until awakening [16]. A previous study demonstrated that the sleep-related increase in serum testosterone levels is linked with the appearance of the first REM sleep episode after about 90 minutes, and the REM latency [17]. The increase in testosterone level is slower when the REM latency is longer [17]. Although mean nocturnal testosterone levels are not correlated with the number of REM episodes [16], sleep fragmentation disrupts the testosterone rhythm, with considerable attenuation of the nocturnal increase in testosterone [17]. The increase in testosterone at the time of sleep, the decrease during the time of awakening, is stable within an individual, although there is large variability among individuals
[18]. Aging is an important factor associated with the morning testosterone level. Generally, middle-aged men have lower morning testosterone levels than healthy younger men, due to a decline in nocturnal testosterone secretion and the amount of nighttime sleep in older men $[19,20]$.

\section{OBSTRUCTIVE SLEEP APNEA AND LOW TESTOSTERONE}

Several studies have confirmed a strong relationship between OSA and low testosterone. Testosterone is associated with pituitary-gonadal function, and OSA is a direct cause of decreased pituitary gonadal function [21]. Both the quantity and quality of sleep affect testosterone levels. Patients with OSA have less REM sleep, reduced deep sleep time, increased nighttime awakenings, sleep fragmentation, and reduced sleep efficiency, which leads to a low testosterone level [6]. Furthermore, several factors, including the apnea-hypopnea index (AHI), the oxygen desaturation index (ODI), nadir oxygen saturation, obesity, and advanced age are associated with the lower testosterone secretions of middleaged men with OSA [22].

The severity of OSA is classified according to the AHI value and the lowest oxygen saturation value. A normal AHI is defined as $\leq 5$, and OSA can be classified as mild (AHI, 5-15), moderate (AHI, 15-30), or severe (AHI, >30) [23]. A negative correlation has been observed between OSA severity and testosterone level; a higher AHI score correlates with a lower testosterone level, suggesting that the severity of apnea is related to decreased testosterone secretions in patients with OSA $[24,25]$. Furthermore, the severity of hypoxia during sleep, as indexed by the ODI and $\mathrm{O}_{2}$ nadir, is strongly correlated with the reduction in testosterone [8]. However, this concept remains controversial; lower testosterone levels have been found not only in patients with mild OSA, but also in elderly obese patients with severe AHI [26].

Obesity is common among patients with OSA, and is associated with increased severity of the disorder. Therefore, body mass index (BMI) may be the primary determinant of testosterone levels in men with OSA [27]. Obesity is strongly linked to low testosterone levels in men, as is increased fat mass, especially abdominal fat. This may be because adipose tissue, especially when inflamed and in an insulin-resistant state, expresses aro- 


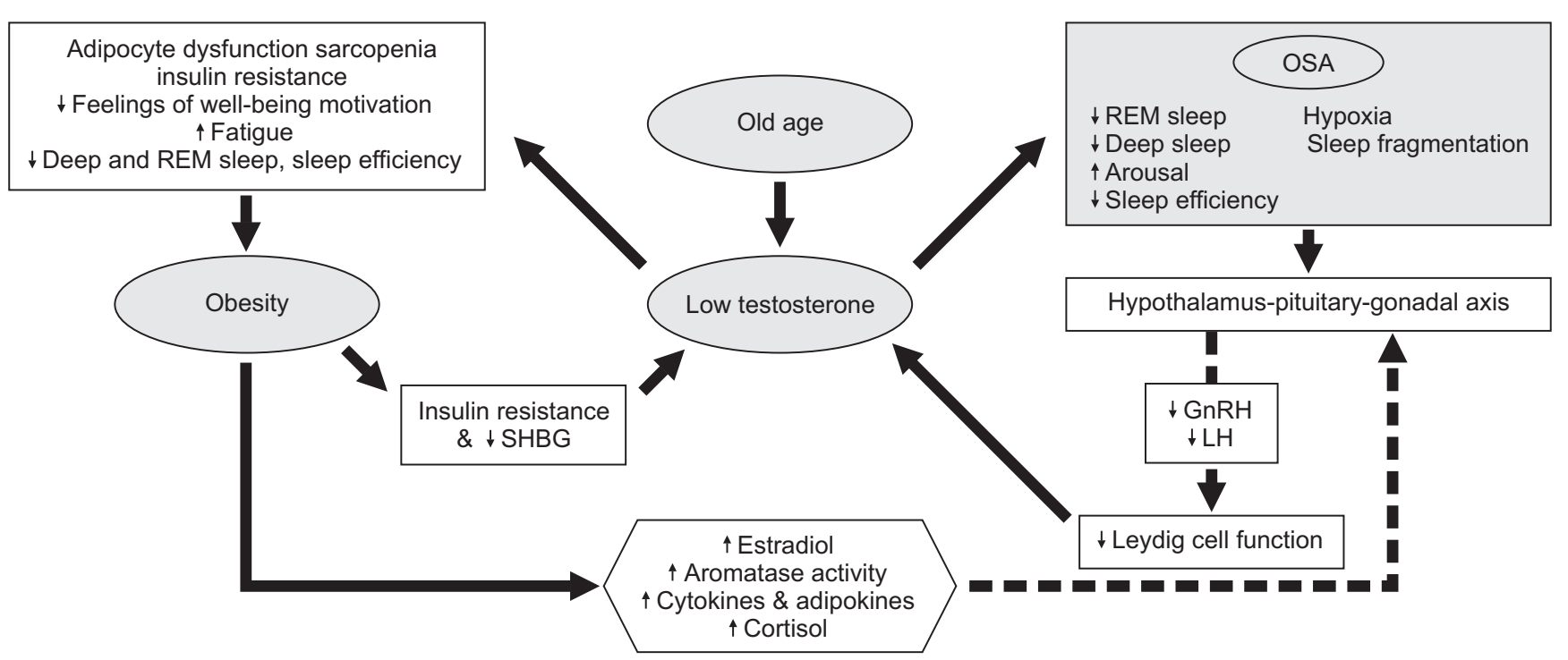

Fig. 1. Potential mechanisms linking obstructive sleep apnea (OSA) and obesity to low testosterone. A bidirectional relationship between testosterone and obesity or OSA is shown. While OSA and obesity lead to lower testosterone, low testosterone promotes obesity and affects sleep quality. REM: rapid eye movement, SHBG: sex hormone binding globulin, GnRH: Gonadotropin-releasing hormone, LH: luteinizing hormone.

matase, which converts testosterone to 17ß-estradiol [28]. Furthermore, obesity reduces the levels of sex hormonebinding globulin (SHBG), which carries testosterone in the bloodstream, due to obesity-associated hyperinsulinemia $[29,30]$. Although obesity leads to a lower testosterone level, low testosterone may also promote obesity [31]. A bidirectional relationship between obesity and low testosterone underpins this association, as indicated by the hypogonadal-obesity cycle and weight loss leading to increased testosterone levels (Fig. 1).

\section{EFFECT OF LOW TESTOSTERONE ON SLEEP QUALITY AND FATIGUE}

While the quantity and quality of sleep lead to reduced testosterone levels, there is also evidence to suggest the reverse. In a cohort study of men aged $\geq 65$ years, those with low testosterone levels experienced decreased sleep efficiency, increased frequency of nighttime awakenings, and reduced deep sleep time [32]. A mouse study showed that loss of testosterone after gonadectomy results in a significant decrease in the amount of deep sleep, which can be treated by testosterone replacement therapy (TRT) [33].

In addition to lower serum testosterone, patients with severe OSA also have higher levels of general fatigue, physical fatigue and mental fatigue, and reduced physical activity. Nadir oxygen saturation is not a significant predictor of fatigue, but a multivariate analysis revealed that testosterone level was the only independent predictor of physical fatigue and reduced activity in patients with OSA [7].

\section{EFFECT OF OBSTRUCTIVE SLEEP APNEA TREATMENT ON TESTOSTERONE}

The effects of OSA treatment on testosterone levels are controversial. A prospective controlled study of uvulopalatopharyngoplasty therapy for OSA showed increased testosterone levels, and improved libido and sexual function, at 3 months post-surgery without significant changes in BMI, serum prolactin, LH, or FSH [34]. Another longitudinal study, of 43 men with severe OSA treated with continuous positive airway pressure (CPAP) therapy, showed a significant increase in total testosterone and SHBG at 3 months after treatment [35]. Although these studies suggest that OSA treatment by CPAP or surgery increases morning plasma testosterone levels within 3 months, the majority of other studies show that CPAP therapy for 1 to 39 months does not affect LH, FSH, or testosterone [36-39]. Unlike the effects of CPAP, there is a linear relationship between weight loss and increased plasma testosterone in obese men [40]. 


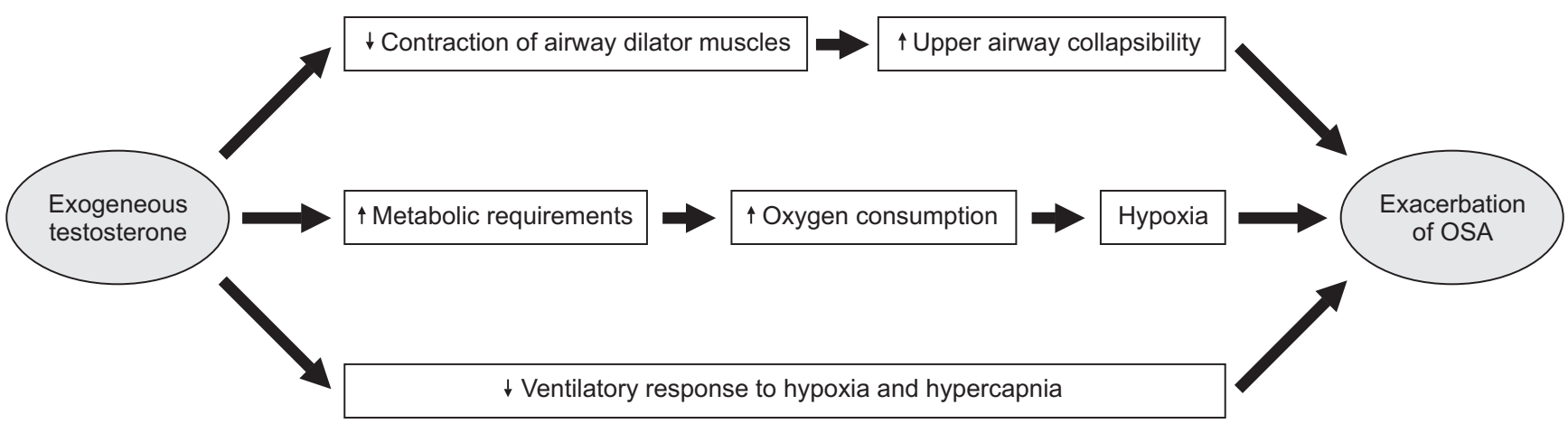

Fig. 2. The plausible mechanisms by which testosterone replacement therapy (TRT) worsens obstructive sleep apnea (OSA). TRT aggravates OSA by several physiologic mechanisms including neuromuscular changes to the airways, changes in metabolic requirements, and changes in the physiologic response to hypoxia and hypercapnia.

\section{EFFECT OF EXOGENOUS TESTOSTERONE ON OBSTRUCTIVE SLEEP APNEA}

Although its effect on OSA remains unclear, exogenous testosterone has been considered to have a noxious effect on OSA. Despite a lack of convincing evidence that TRT aggravates OSA, in current guidelines TRT is contraindicated in the presence of untreated OSA [41]. Although low testosterone may affect overall sleep quality, which is improved by replacement doses, large doses of exogenous testosterone are associated with abnormalities in sleep duration and architecture. Several studies have shown that TRT exacerbates OSA symptoms, the increase in the AHI, and the decrease in oxygen saturation [42-47]. The effect of testosterone on OSA is not exerted by changing the dimensions of the upper airway; instead, testosterone most likely contributes to OSA via central mechanisms.

There are a variety of possible physiological mechanisms by which TRT exacerbates OSA, including morphological and neuromuscular changes to the airway, changes in metabolic requirements, and changes in physiological responses to hypoxemia and hypercapnia. Dilatation of the upper airway depends on contraction of the airway dilator muscles (e.g., the genioglossus), an effect mediated by parallel serotoninergic and noradrenergic neurons; both types of neuron may be impacted by age and testosterone level $[22,48]$. Alternative explanations include the possibility of higher metabolic requirements with elevated testosterone levels, which may result in greater oxygen consumption that in turn could lead to hypoxia [41]. Other plausible explanations include a role for testosterone in the neural response pathways to hypoxia and hypercapnia [49]. Fluctuating testosterone levels may also impact on the ventilatory response to hypoxia and hypercapnia, which could explain the higher rates of OSA seen in men on TRT [47,50] (Fig. 2).

Development of the signs and symptoms of OSA during TRT requires assessment by polysomnography and, potentially, treatment with CPAP. If the patient is unresponsive or cannot tolerate CPAP, the testosterone dose must be reduced or discontinued. Furthermore, OSA has been proposed to be a risk factor for secondary polycythemia [51] and TRT exacerbates polycythemia in some patients [52]. This should be kept in mind in patients with OSA and hypogonadism who are considering TRT.

\section{OBSTRUCTIVE SLEEP APNEA AND SEXUAL DYSFUNCTION}

The men with OSA are also more prone to suffering from associated complications like low libido, impotence, and ED. Severe OSA was clearly associated with $\mathrm{ED}$, although this relationship was very weak in patients with mild or moderate OSA [53]. A recent metaanalysis reported that the relative risk of ED in OSA patients was 1.82 [54]. Although the effects of OSA treatment on testosterone levels remain unclear, there are more positive data for the improvement in sexual dysfunction with OSA treatment regardless of testosterone level. CPAP resolved ED in $75 \%$ of OSA patients, resulting in significant improvement in quality of life [55]. A pilot study showed that positive additive effects of TRT to phosphodiesterase type 5 inhibitors in hypogonadal men with OSA receiving CPAP therapy. 
However, it is not yet clear whether similar benefits can be achieved with CPAP alone without TRT, which should be confirmed in larger controlled studies.

\section{CONCLUSIONS}

Testosterone shows circadian variation, but its pattern is not as same as cortisol. Sleep-related increase in serum testosterone is linked with the appearance of first REM sleep and requires 3 hours of deep sleep. Although the relationship between testosterone and OSA are complex and not yet completely understood, OSA may contribute to low testosterone because hypoxia and sleep fragmentation. Furthermore, obesity and advanced age may account for lower testosterone secretion levels in middle-aged men with OSA. Although the effects of OSA treatment on testosterone levels remain unclear, OSA treatment may help improve sexual function, especially in men with severe OSA. However, TRT should be probably avoided in patients with severe untreated OSA because TRT may worsen OSA in some patients.

\section{Disclosure}

The authors have no potential conflicts of interest to disclose.

\section{Author Contribution}

Writing (original draft): Kim SD. Writing (review \& editing): Cho KS.

\section{REFERENCES}

1. Park CY, Hong JH, Lee JH, Lee KE, Cho HS, Lim SJ, et al. Clinical effect of surgical correction for nasal pathology on the treatment of obstructive sleep apnea syndrome. PLoS One 2014;9:e98765.

2. Nieto FJ, Young TB, Lind BK, Shahar E, Samet JM, Redline S, et al. Association of sleep-disordered breathing, sleep apnea, and hypertension in a large community-based study. Sleep Heart Health Study. JAMA 2000;283:1829-36.

3. Gottlieb DJ, Yenokyan G, Newman AB, O'Connor GT, Punjabi NM, Quan SF, et al. Prospective study of obstructive sleep apnea and incident coronary heart disease and heart failure: the sleep heart health study. Circulation 2010;122:352-60.

4. Redline S, Yenokyan G, Gottlieb DJ, Shahar E, O'Connor GT, Resnick HE, et al. Obstructive sleep apnea-hypopnea and incident stroke: the sleep heart health study. Am J Respir Crit Care Med 2010;182:269-77.

5. Teloken PE, Smith EB, Lodowsky C, Freedom T, Mulhall JP. Defining association between sleep apnea syndrome and erectile dysfunction. Urology 2006;67:1033-7.

6. Wittert G. The relationship between sleep disorders and testosterone. Curr Opin Endocrinol Diabetes Obes 2014;21:239-43.

7. Bercea RM, Mihaescu T, Cojocaru C, Bjorvatn B. Fatigue and serum testosterone in obstructive sleep apnea patients. Clin Respir J 2015;9:342-9.

8. Viana A Jr, Daflon AC, Couto A, Neves D, de Araujo-Melo $\mathrm{MH}$, Capasso R. Nocturnal hypoxemia is associated with low testosterone levels in overweight males and older men with normal weight. J Clin Sleep Med 2017;13:1395-401.

9. Li Z, Tang T, Wu W, Gu L, Du J, Zhao T, et al. Efficacy of nasal continuous positive airway pressure on patients with OSA with erectile dysfunction and low sex hormone levels. Respir Med 2016;119:130-4.

10. McLaughlin Crabtree V, Williams NA. Normal sleep in children and adolescents. Child Adolesc Psychiatr Clin N Am 2009;18:799-811.

11. Markov D, Goldman M. Normal sleep and circadian rhythms: neurobiologic mechanisms underlying sleep and wakefulness. Psychiatr Clin North Am 2006;29:841-53.

12. Dorffner G, Vitr M, Anderer P. The effects of aging on sleep architecture in healthy subjects. Adv Exp Med Biol 2015;821: 93-100.

13. Li J, Vitiello MV, Gooneratne NS. Sleep in normal aging. Sleep Med Clin 2018;13:1-11.

14. Miyatake A, Morimoto Y, Oishi T, Hanasaki N, Sugita Y, Iijima S, et al. Circadian rhythm of serum testosterone and its relation to sleep: comparison with the variation in serum luteinizing hormone, prolactin, and cortisol in normal men. J Clin Endocrinol Metab 1980;51:1365-71.

15. Luboshitzky R, Aviv A, Hefetz A, Herer P, Shen-Orr Z, Lavie $L$, et al. Decreased pituitary-gonadal secretion in men with obstructive sleep apnea. J Clin Endocrinol Metab 2002;87:3394-8.

16. Luboshitzky R, Herer P, Levi M, Shen-Orr Z, Lavie P. Relationship between rapid eye movement sleep and testosterone secretion in normal men. J Androl 1999;20:731-7.

17. Luboshitzky R, Zabari Z, Shen-Orr Z, Herer P, Lavie P. Disruption of the nocturnal testosterone rhythm by sleep fragmentation in normal men. J Clin Endocrinol Metab 2001;86: 1134-9.

18. Axelsson J, Ingre M, Akerstedt T, Holmbäck U. Effects of acutely displaced sleep on testosterone. J Clin Endocrinol Metab 2005;90:4530-5.

19. Luboshitzky R, Shen-Orr Z, Herer P. Middle-aged men se- 
crete less testosterone at night than young healthy men. J Clin Endocrinol Metab 2003;88:3160-6.

20. Penev PD. Association between sleep and morning testosterone levels in older men. Sleep 2007;30:427-32.

21. Soukhova-O'Hare GK, Shah ZA, Lei Z, Nozdrachev AD, Rao CV, Gozal D. Erectile dysfunction in a murine model of sleep apnea. Am J Respir Crit Care Med 2008;178:644-50.

22. Molina FD, Suman M, Carvalho TB, Piatto VB, Taboga SR, Maniglia JV, et al. Evaluation of testosterone serum levels in patients with obstructive sleep apnea syndrome. Braz J Otorhinolaryngol 2011;77:88-95.

23. Ruehland WR, Rochford PD, O’Donoghue FJ, Pierce RJ, Singh P, Thornton AT. The new AASM criteria for scoring hypopneas: impact on the apnea hypopnea index. Sleep 2009;32: 150-7.

24. Gambineri A, Pelusi C, Pasquali R. Testosterone levels in obese male patients with obstructive sleep apnea syndrome: relation to oxygen desaturation, body weight, fat distribution and the metabolic parameters. J Endocrinol Invest 2003;26: 493-8.

25. Luboshitzky R, Lavie L, Shen-Orr Z, Herer P. Altered luteinizing hormone and testosterone secretion in middle-aged obese men with obstructive sleep apnea. Obes Res 2005;13:780-6.

26. Araujo AB, O’Donnell AB, Brambilla DJ, Simpson WB, Longcope C, Matsumoto AM, et al. Prevalence and incidence of androgen deficiency in middle-aged and older men: estimates from the Massachusetts Male Aging Study. J Clin Endocrinol Metab 2004;89:5920-6.

27. Canguven O, Salepci B, Albayrak S, Selimoglu A, Balaban M, Bulbul M. Is there a correlation between testosterone levels and the severity of the disease in male patients with obstructive sleep apnea? Arch Ital Urol Androl 2010;82:143-7.

28. Simpson ER, Clyne C, Rubin G, Boon WC, Robertson K, Britt K, et al. Aromatase--a brief overview. Annu Rev Physiol 2002; 64:93-127.

29. Pasquali R, Casimirri F, Cantobelli S, Melchionda N, Morselli Labate AM, Fabbri R, et al. Effect of obesity and body fat distribution on sex hormones and insulin in men. Metabolism 1991;40:101-4.

30. Gambineri A, Pasquali R. Testosterone therapy in men: clinical and pharmacological perspectives. J Endocrinol Invest 2000;23:196-214.

31. Kelly DM, Jones TH. Testosterone and obesity. Obes Rev 2015;16:581-606

32. Barrett-Connor E, Dam TT, Stone K, Harrison SL, Redline S, Orwoll E. The association of testosterone levels with overall sleep quality, sleep architecture, and sleep-disordered breathing. J Clin Endocrinol Metab 2008;93:2602-9.
33. Paul KN, Laposky AD, Turek FW. Reproductive hormone replacement alters sleep in mice. Neurosci Lett 2009;463:239-43.

34. Santamaria JD, Prior JC, Fleetham JA. Reversible reproductive dysfunction in men with obstructive sleep apnoea. Clin Endocrinol (Oxf) 1988;28:461-70.

35. Grunstein RR, Handelsman DJ, Lawrence SJ, Blackwell C, Caterson ID, Sullivan CE. Neuroendocrine dysfunction in sleep apnea: reversal by continuous positive airways pressure therapy. J Clin Endocrinol Metab 1989;68:352-8.

36. Macrea MM, Martin TJ, Zagrean L. Infertility and obstructive sleep apnea: the effect of continuous positive airway pressure therapy on serum prolactin levels. Sleep Breath 2010;14:253-7.

37. Hoekema A, Stel AL, Stegenga B, van der Hoeven JH, Wijkstra PJ, van Driel MF, et al. Sexual function and obstructive sleep apnea-hypopnea: a randomized clinical trial evaluating the effects of oral-appliance and continuous positive airway pressure therapy. J Sex Med 2007;4:1153-62.

38. Meston N, Davies RJ, Mullins R, Jenkinson C, Wass JA, Stradling JR. Endocrine effects of nasal continuous positive airway pressure in male patients with obstructive sleep apnoea. J Intern Med 2003;254:447-54.

39. Bratel T, Wennlund A, Carlström K. Pituitary reactivity, androgens and catecholamines in obstructive sleep apnoea. Effects of continuous positive airway pressure treatment (CPAP). Respir Med 1999;93:1-7.

40. Grossmann M. Low testosterone in men with type 2 diabetes: significance and treatment. J Clin Endocrinol Metab 2011;96: 2341-53.

41. Hanafy HM. Testosterone therapy and obstructive sleep apnea: is there a real connection? J Sex Med 2007;4:1241-6.

42. Cistulli PA, Grunstein RR, Sullivan CE. Effect of testosterone administration on upper airway collapsibility during sleep. Am J Respir Crit Care Med 1994;149:530-2.

43. Schneider BK, Pickett CK, Zwillich CW, Weil JV, McDermott MT, Santen RJ, et al. Influence of testosterone on breathing during sleep. J Appl Physiol (1985) 1986;61:618-23.

44. Matsumoto AM, Sandblom RE, Schoene RB, Lee KA, Giblin EC, Pierson DJ, et al. Testosterone replacement in hypogonadal men: effects on obstructive sleep apnoea, respiratory drives, and sleep. Clin Endocrinol (Oxf) 1985;22:713-21.

45. Hajjar RR, Kaiser FE, Morley JE. Outcomes of long-term testosterone replacement in older hypogonadal males: a retrospective analysis. J Clin Endocrinol Metab 1997;82:3793-6.

46. Hoyos CM, Killick R, Yee BJ, Grunstein RR, Liu PY. Effects of testosterone therapy on sleep and breathing in obese men with severe obstructive sleep apnoea: a randomized placebocontrolled trial. Clin Endocrinol (Oxf) 2012;77:599-607.

47. Killick R, Wang D, Hoyos CM, Yee BJ, Grunstein RR, Liu 
PY. The effects of testosterone on ventilatory responses in men with obstructive sleep apnea: a randomised, placebocontrolled trial. J Sleep Res 2013;22:331-6.

48. Ylmaz M, Bayazit YA, Ciftci TU, Erdal ME, Urhan M, Kokturk $\mathrm{O}$, et al. Association of serotonin transporter gene polymorphism with obstructive sleep apnea syndrome. Laryngoscope 2005;115:832-6.

49. Tatsumi K, Hannhart B, Pickett CK, Weil JV, Moore LG. Effects of testosterone on hypoxic ventilatory and carotid body neural responsiveness. Am J Respir Crit Care Med 1994;149: 1248-53.

50. Liu PY, Yee B, Wishart SM, Jimenez M, Jung DG, Grunstein $\mathrm{RR}$, et al. The short-term effects of high-dose testosterone on sleep, breathing, and function in older men. J Clin Endocrinol Metab 2003;88:3605-13.

51. Choi JB, Loredo JS, Norman D, Mills PJ, Ancoli-Israel S,
Ziegler MG, et al. Does obstructive sleep apnea increase hematocrit? Sleep Breath 2006;10:155-60.

52. Bachman E, Travison TG, Basaria S, Davda MN, Guo W, Li $\mathrm{M}$, et al. Testosterone induces erythrocytosis via increased erythropoietin and suppressed hepcidin: evidence for a new erythropoietin/hemoglobin set point. J Gerontol A Biol Sci Med Sci 2014;69:725-35.

53. Margel D, Cohen M, Livne PM, Pillar G. Severe, but not mild, obstructive sleep apnea syndrome is associated with erectile dysfunction. Urology 2004;63:545-9.

54. Liu L, Kang R, Zhao S, Zhang T, Zhu W, Li E, et al. Sexual dysfunction in patients with obstructive sleep apnea: a systematic review and meta-analysis. J Sex Med 2015;12:1992-2003.

55. Gonçalves MA, Guilleminault C, Ramos E, Palha A, Paiva T. Erectile dysfunction, obstructive sleep apnea syndrome and nasal CPAP treatment. Sleep Med 2005;6:333-9. 